Article

\title{
Polyolefin Backbone Substitution in Binders for Low Temperature Powder Injection Moulding Feedstocks
}

Berenika Hausnerova $^{1,2, *}$, Ivo Kuritka ${ }^{2,3}$ and Davit Bleyan ${ }^{1,2}$

1 Department of Production Engineering, Faculty of Technology, Tomas Bata University in Zlin, nam. T.G. Masaryka 5555, Zlin 760 01, Czech Republic; E-Mail: bleyan@ft.utb.cz

2 Centre of Polymer Systems, University Institute, Tomas Bata University in Zlin, Nad Ovcirnou 3685, Zlin 760 01, Czech Republic; E-Mail: kuritka@ft.utb.cz

3 Polymer Centre, Faculty of Technology, Tomas Bata University in Zlin, nam. T.G. Masaryka 5555, Zlin 760 01, Czech Republic

* Author to whom correspondence should be addressed; E-Mail: hausnerova@ft.utb.cz; Tel.: +420-576-035-167; Fax: +420-576-031-444.

Received: 3 January 2014; in revised form: 20 February 2014 / Accepted: 21 February 2014 / Published: 27 February 2014

\begin{abstract}
This paper reports the substitution of polyolefin backbone binder components with low melting temperature carnauba wax for powder injection moulding applications. The effect of various binder compositions of $\mathrm{Al}_{2} \mathrm{O}_{3}$ feedstock on thermal degradation parameters is investigated by thermogravimetric analysis. Within the experimental framework 29 original feedstock compositions were prepared and the superiority of carnauba wax over the polyethylene binder backbone was demonstrated in compositions containing polyethylene glycol as the initial opening agent and governing the proper mechanism of the degradation process. Moreover, the replacement of synthetic polymer by the natural wax contributes to an increase of environmental sustainability of modern industrial technologies.
\end{abstract}

Keywords: binder; polyolefin; carnauba wax; debinding; thermogravimetric analysis; powder injection moulding 


\section{Introduction}

Powder Injection Moulding (PIM) has attracted great attention in the production of net-shape, high precision parts for the medical, aerospace and automotive industry in high production volumes due to its low processing cost and time effectiveness. PIM offers clear advantages over other net-shaping techniques, including pressing and casting, for high volume, complex geometry parts of tight dimensional tolerances [1].

During the process, metallic or ceramic powder is mixed with polymeric substances to create a homogeneous feedstock which is moulded into the desired shape after pelletizing. To extract the binder the moulded compacts are treated by chemical (solvent) and thermal routes in the step called debinding. Then, during the final stage the porous products are sintered to a density near the theoretical one.

Such a multi-step processing necessarily evolves often contradictory or inconsistent requirements on the composition of binder system, which must ensure agglomeration-free and uniform distribution of powder particles within feedstock during mixing, and provide the feedstock with moderate viscosity during injection moulding. Then, during debinding it must have steady thermal degradation properties and high yield stress to retain the shape of the product during binder burnout up to early sintering [2].

Furthermore, as the PIM technology expands to reactive powders, an additional requirement on binder appears - the need to mix and mould the feedstock at low temperatures in order to diminish the oxidation reactions at elevated temperatures. Additional benefits are energy and material (with protective inert atmospheres such as argon) savings through mixing and moulding steps of the process.

Lack of any of these requirements may result in cracks, voids, distortions, non-uniform shrinkage and warping in the final products [3,4]. Clearly, in order to provide feedstocks tailored to the process demands, multi-component binder systems must be used. A typical binder system includes a thermoplastic polymer (polyolefin) as a backbone, waxes and processing aids $[5,6]$.

In this paper, low density polyethylene (PE) will be substituted with a carnauba wax (CW) and polyethylene glycols (PEG) of different molecular weights. Thermal and combined solvent-thermal debinding of aluminum oxide feedstocks based on PE and CW will be analysed by themogravimetry.

In a previous paper [7] it has been shown that due to the relatively high hygroscopicity of fine alumina powder it imposes rather sophisticated requirements on binder system. A lot of effort has been done [8-10] to investigate the thermal degradation properties of thermoplastic feedstocks based on aluminum oxide occurring as evaporation, thermal degradation and oxidative degradation (in the case of oxygen presence in the atmosphere). Trunec and Cihlar [8] have shown for 60 vol.\% feedstock containing ethylene-vinyl acetate copolymer, paraffin wax and stearic acid (SA) in nitrogen (flow rate $3.3 \mathrm{~cm}^{3} \cdot \mathrm{s}^{-1}$, heating rate $10{ }^{\circ} \mathrm{C} \cdot \mathrm{min}^{-1}$ ) that high binder loss rates may not allow uniform binder redistribution, resulting in inhomogeneous saturation of the body with binder with porous surface layers and excess binder in the body center, leading to the formation of cracks.

Krauss et al. [9] demonstrated that the solvent (water) extraction of PEG from 55 vol.\% alumina feedstock containing polyvinyl butyral as a backbone, PEG and SA is diffusion-controlled, since the weight loss of PEG is square root time dependent. They also developed a mathematical model based on a core-shrinkage mechanism with diffusion in the porous region, and confirmed its good agreement with the experimental data. 
Voorhees et al. [10] investigated thermal degradation products of PEG in an alumina feedstock and proposed the concept of the major pyrolysis reactions. The thermogravimetric curves showed that alumina has no effect on PEG/alumina feedstock thermal degradation products.

Finally, it should be mentioned that providing conclusions of general relevance is a rather complicated task, since in the majority of cases the debinding mechanism(s) of one component is dependent on the other components of a binder system, and systematic study of the effect of particular binder components and their concentration in the bulk binder is still missing. The complexity of the compositions used requires detailed studies on each component. Here we report on the role of PEG with different molar mass, polyethylene and paraffin and substitution of these two components by $\mathrm{CW}$ from natural sources.

\section{Results and Discussion}

\subsection{Design of Binder Composition}

The binder components employed in the study were selected with respect to the requirements described in the Introduction. The first group of binder compositions (Table 1) contained low density polyethylene (PE). Huang and Hsu [11] studied the effect of high and low density polyethylenes and their blend (50:50) on the properties of $316 \mathrm{~L}$ stainless steel feedstocks containing also paraffin wax (PW) and stearic acid (SA) and found out that low density PE results in more favorable flow behavior, however high density PE provides better dimensional stability of the molded part, and thus the combination of both PEs was recommended to gain the maximum benefits.

Table 1. Polyolefin-based feedstocks.

\begin{tabular}{|c|c|c|c|c|c|c|c|}
\hline Name & $\begin{array}{c}\text { PE } \\
\text { wt.\% }\end{array}$ & $\begin{array}{c}\text { PW } \\
\text { wt.\% }\end{array}$ & $\begin{array}{c}\text { PEG1000 } \\
\text { wt. } \% \\
\end{array}$ & $\begin{array}{c}\text { PEG4000 } \\
\text { wt.\% }\end{array}$ & $\begin{array}{c}\text { PEG6000 } \\
\text { wt. } \% \\
\end{array}$ & $\begin{array}{c}\text { SA } \\
\text { wt.\% } \%\end{array}$ & $\begin{array}{c}\phi_{m} \\
\text { wt. } \%\end{array}$ \\
\hline F1 & 20 & 20 & 10 & 39 & 10 & 1 & 84.7 \\
\hline $\mathrm{F} 2$ & 10 & 30 & 10 & 39 & 10 & 1 & 85.2 \\
\hline F3 & 20 & 20 & 10 & 39 & 10 & 1 & 85.2 \\
\hline F4 & 40 & - & 20 & 39 & - & 1 & 85.2 \\
\hline F5 & 40 & - & 10 & 25 & 20 & 5 & 85.2 \\
\hline F6a & & & & & & & 85.2 \\
\hline F6b & 40 & 10 & - & 20 & 29 & 1 & 85.5 \\
\hline F6c & 40 & 10 & - & 20 & 29 & 1 & 85.9 \\
\hline F6d & & & & & & & 86.5 \\
\hline F7a & & & & & & & 85.2 \\
\hline F7b & 40 & 10 & - & 10 & 39 & 1 & 85.5 \\
\hline F7c & & & & & & & 85.8 \\
\hline F8a & & & & & & & 85.2 \\
\hline $\mathrm{F} 8 \mathrm{~b}$ & 50 & - & - & 10 & 39 & 1 & 85.5 \\
\hline F8c & & & & & & & 85.8 \\
\hline F9 & 20 & 30 & - & 20 & 29 & 1 & 85.5 \\
\hline F10 & 30 & 30 & - & - & 39 & 1 & 85.2 \\
\hline F11 & 35 & 30 & - & 15 & 19 & 1 & 85.2 \\
\hline F12 & 30 & 40 & - & 12 & 13 & 5 & 85.6 \\
\hline F13 & 31 & 33 & - & 15 & 16 & 5 & 85.2 \\
\hline F14 & 20 & 30 & 10 & 15 & 22 & 3 & 85.5 \\
\hline F15 & 25 & 36 & 10 & 10 & 16 & 3 & 85.2 \\
\hline F16 & 20 & 10 & 20 & 20 & 27 & 3 & 85.2 \\
\hline
\end{tabular}


Hsu et al. [12] compared PW, carnauba (CW), polyethylene wax (PEW) and acrawax (AW) in 56 vol.\% $304 \mathrm{~L}$ stainless steel feedstocks containing 22 vol.\% of low density polyethylene (PE) and demonstrated that usage of PW-PE based binders resulted in the highest tensile strength of the sintered parts, however polar waxes (CW and $\mathrm{AW}$ ) improved the process-ability of the feedstock due to enhanced interactions with powder. Furthermore, AW containing strong polar amide groups and short hydrocarbon chain ends provides the highest carbon content in brown (debinded) parts, and also is less compatible with PE than $\mathrm{CW}$. In order to prevent possible separation and aggregation of PE molecules from the binder during mixing as well as due to the better mechanical properties of $\mathrm{CW}$ based feedstocks than AW ones, the former $(\mathrm{CW})$ has been employed as a backbone of the second feedstocks group in this study (Table 2).

Table 2. Non-polyolefin based feedstocks.

\begin{tabular}{cccccccc}
\hline Name & $\begin{array}{c}\text { CW } \\
\text { wt.\% }\end{array}$ & $\begin{array}{c}\text { PW } \\
\text { wt.\% }\end{array}$ & $\begin{array}{c}\text { PEG1000 } \\
\text { wt.\% }\end{array}$ & $\begin{array}{c}\text { PEG4000 } \\
\text { wt.\% }\end{array}$ & $\begin{array}{c}\text { PEG6000 } \\
\text { wt.\% }\end{array}$ & $\begin{array}{c}\text { SA } \\
\text { wt.\% }\end{array}$ & $\begin{array}{c}\boldsymbol{\phi}_{\mathbf{m}} \\
\text { wt.\% }\end{array}$ \\
\hline F17 & - & 45 & - & - & 50 & 5 & 84.7 \\
F18 & - & 40 & - & 15 & 40 & 5 & 84.2 \\
F19 & 25 & 30 & - & 20 & 20 & 5 & 84.5 \\
F20 & 35 & 20 & 10 & 10 & 20 & 5 & 84.2 \\
F21 & 40 & 10 & 10 & 12 & 25 & 3 & 84.2 \\
F22 & 40 & 10 & 10 & 14 & 25 & 1 & 85.2 \\
\hline
\end{tabular}

Waxes and polyethylene glycol are common components of both feedstocks investigated. With low melting temperatures, waxes can be removed at the early stage of debinding consequently creating a network of pores which will promote the thermal degradation of higher molecular weight polymers. Waxes also increase the wetting characteristics of the powder, ensuring uniform coating of the particles.

In this study, the effect of molecular weight of polyethylene glycols is also considered. Yang and Hon [13] and Yang et al. [14] studied the influence of low molecular weight polyethylene glycol (PEG) on rheological and debinding characteristics of aluminum oxide feedstock containing PEG, PE wax and SA. Higher content of low-molecular PEG improved the flow-ability of the bulk feedstock. As a processing aid, stearic acid (SA) lubricating and wetting powder particles [15] is used. As it has been reported [16], it plays a critical role in creating homogenous mixture as well as insuring higher rate of binder extraction throughout the network of pores created in body during early stage of thermal debinding.

\subsection{Thermal Analysis of Feedstocks}

The TGA results are presented through the peak degradation temperatures and corresponding mass losses depicted in Table 3. The thermal degradation of highly filled systems proceeds evidently in several steps, however, they are relatively poorly resolved due to the influence of transport processes and the data analysis was elaborated with the aid of numerical derivation. The peak degradation temperature on the negative derivative TGA curve corresponds to the inflexion point in the respective thermal degradation step signalizing thus the highest mass loss rate temperature. In several cases of even less resolved peaks, higher derivatives were calculated and the position of the significant points was refined. If needed, the onset temperatures were obtained from common analytical procedure 
employing the intersection of the horizontal line at the transition between the distinguishable steps and the tangent in the inflection point [6]. During the debinding stage three main processes are involved: evaporation, thermal degradation and oxidative degradation [17,18]. The low molecular weight compounds or fragments of polymers are mainly evaporated by propagation towards the specimen surface, while high molecular weight components are subjected to thermal degradation [19].

Table 3. Feedstock thermal degradation peaks in percentage of weight loss.

\begin{tabular}{|c|c|c|c|c|c|c|c|c|}
\hline \multirow{2}{*}{ Feedstock } & \multicolumn{2}{|c|}{ Peak 1} & \multicolumn{2}{|c|}{ Peak 2} & \multicolumn{2}{|c|}{ Peak 3} & \multicolumn{2}{|c|}{ Peak 4} \\
\hline & {$\left[{ }^{\circ} \mathbf{C}\right]$} & [wt.\%] & {$\left[{ }^{\circ} \mathrm{C}\right]$} & [wt.\%] & {$\left[{ }^{\circ} \mathbf{C}\right]$} & [wt.\%] & {$\left[{ }^{\circ} \mathrm{C}\right]$} & [wt.\%] \\
\hline $\mathrm{F} 1$ & 185 & 0.36 & 223 & 11.61 & - & - & 455 & 4.98 \\
\hline $\mathrm{F} 2$ & 180 & 0.19 & 215 & 11.92 & - & - & 447 & 4.8 \\
\hline F3 & 175 & 0.51 & 215 & 10.09 & - & - & 465 & 5.77 \\
\hline F4 & 171 & 0.33 & 223 & 10.15 & 348 & 4.33 & 469 & 2.11 \\
\hline F5 & 175 & 0.21 & 238 & 9.35 & 349 & 4.53 & 473 & 2.2 \\
\hline F6a & 176 & 0.15 & 251 & 8.82 & 352 & 4.97 & 473 & 2.18 \\
\hline F6b & 184 & 0.15 & 234 & 7.77 & 338 & 4.9 & 472 & 2.21 \\
\hline F6c & 192 & 0.17 & 243 & 8.47 & 348 & 4.17 & 470 & 1.82 \\
\hline F6d & 192 & 0.14 & 230 & 7.8 & 338 & 4.42 & 457 & 1.95 \\
\hline F7a & 189 & 0.11 & 242 & 8.11 & 356 & 3.92 & 462 & 1.94 \\
\hline F7b & 197 & 0.31 & 240 & 8.62 & 341 & 4.14 & 471 & 2.14 \\
\hline F7c & 194 & 0.19 & 238 & 8.21 & 335 & 4.34 & 453 & 2.1 \\
\hline F8a & 181 & 0.15 & 232 & 7.67 & 348 & 6.38 & 454 & 2.67 \\
\hline $\mathrm{F} 8 \mathrm{~b}$ & 185 & 0.19 & 237 & 7.34 & 349 & 5.1 & 446 & 2.23 \\
\hline $\mathrm{F} 8 \mathrm{c}$ & 188 & 0.18 & 234 & 6.9 & 344 & 5.3 & 450 & 2.34 \\
\hline F9 & 180 & 0.23 & 204 & 7.51 & 352 & 4.48 & 459 & 1.29 \\
\hline F10 & 189 & 0.22 & 205 & 7.63 & 350 & 4.6 & 456 & 1.54 \\
\hline F11 & 205 & 0.32 & - & - & 354 & 13.9 & 462 & 1.95 \\
\hline F12 & 201 & 0.29 & 245 & 7.62 & 348 & 4.62 & 460 & 1.85 \\
\hline F13 & 207 & 0.35 & 251 & 8.29 & 349 & 4.88 & 455 & 1.96 \\
\hline F14 & 176 & 0.36 & 219 & 9.52 & - & - & 448 & 5.16 \\
\hline F15 & 203 & 0.38 & 248 & 9.25 & 348 & 4.04 & 455 & 1.74 \\
\hline F16 & 171 & 0.23 & 200 & 9.88 & - & - & 458 & 5 \\
\hline F17 & 174 & 0.18 & 208 & 10.03 & - & - & 442 & 4.64 \\
\hline F18 & 172 & 0.12 & 209 & 12.68 & - & - & 442 & 4.51 \\
\hline F19 & 190 & 0.16 & 231 & 9.07 & - & - & 460 & 6.42 \\
\hline F20 & 194 & 0.17 & 245 & 8.89 & 341 & 4.56 & 458 & 2.16 \\
\hline $\mathrm{F} 21$ & 189 & 0.16 & - & - & 346 & 13.71 & 460 & 2.08 \\
\hline F22 & 195 & 0.23 & 247 & 8.74 & 345 & 4.45 & 459 & 1.91 \\
\hline
\end{tabular}

For polyolefins, the thermal degradation occurs by random polymer chain scission [20]. The debinding in an air atmosphere involves oxidative degradation, which acts from the surface towards the center of the specimens, while being limited by the diffusion of oxygen into the binder components and their extraction towards the surface [21].

For PE-based feedstocks, the earliest mass loss was exhibited at $171{ }^{\circ} \mathrm{C}$ for $\mathrm{F} 4$ (40 PE/20 PEG1000/39 PEG4000/1 SA wt.\%.) and F16 (20 PE/10 PW/20 PEG1000/20 PEG4000/27 PEG 6000/3 
SA wt.\%.) compositions by 0.33 and 0.23 wt.\% respectively, while the earliest weight drop for $\mathrm{CW} / \mathrm{PW}$ based compositions took place at $172{ }^{\circ} \mathrm{C}$ for feedstock $\mathrm{F} 18$ by only $0.12 \mathrm{wt} . \%$.

$\mathrm{CW}$ is composed of a mixture of linear chain esters, alcohols, acids and hydrocarbons. It exhibits the smallest linear expansion in temperature range $22-52{ }^{\circ} \mathrm{C}$ compared to other waxes [22].

For polyethylene glycol (PEG), the polymer degradation process leads to a reduction in molecular weight and to diminution of chain length, resulting from the bond scission in the backbone of the macromolecules as in the case of linear polymers [23]. The TGA data (Table 3) shows that higher overall content of PEG significantly lowers the starting temperature of thermal degradation.

The role of different molecular weight PEG on gradual thermal debinding can be seen from Figures 1 and 2 comparing two contrasting TG curves for PE based feedstock F10 (30 PE/30 PW/39 PEG6000/1 SA wt.\%) and F14 (20 PE/30 PW/10 PEG1000/15 PEG4000/22 PEG6000/3 SA wt.\%). For feedstock F10 the first mass loss starts at around $189^{\circ} \mathrm{C}$ with a sharp drop which is linked to start of the evaporation or degradation of PW and PEG with the lowest molecular mass. Meanwhile, the higher amount of low molecular PEG1000 in feedstock F14 developed a slight slope by the start point at $176{ }^{\circ} \mathrm{C}$. The second stage for both (F10 and F14) feedstocks starting at 205 and $219{ }^{\circ} \mathrm{C}$, respectively, depicts the evaporation of volatile $\mathrm{PE}$ degradation products. The weight loss of 13.79 and 15.08 wt. $\%$ indicates of a full extraction of the binder system at 456 and $448{ }^{\circ} \mathrm{C}$, respectively.

Figure 1. TGA weight loss and corresponding derivative curve for F10 (30 PE/30 PW/39 PEG6000/1 SA wt.\%).

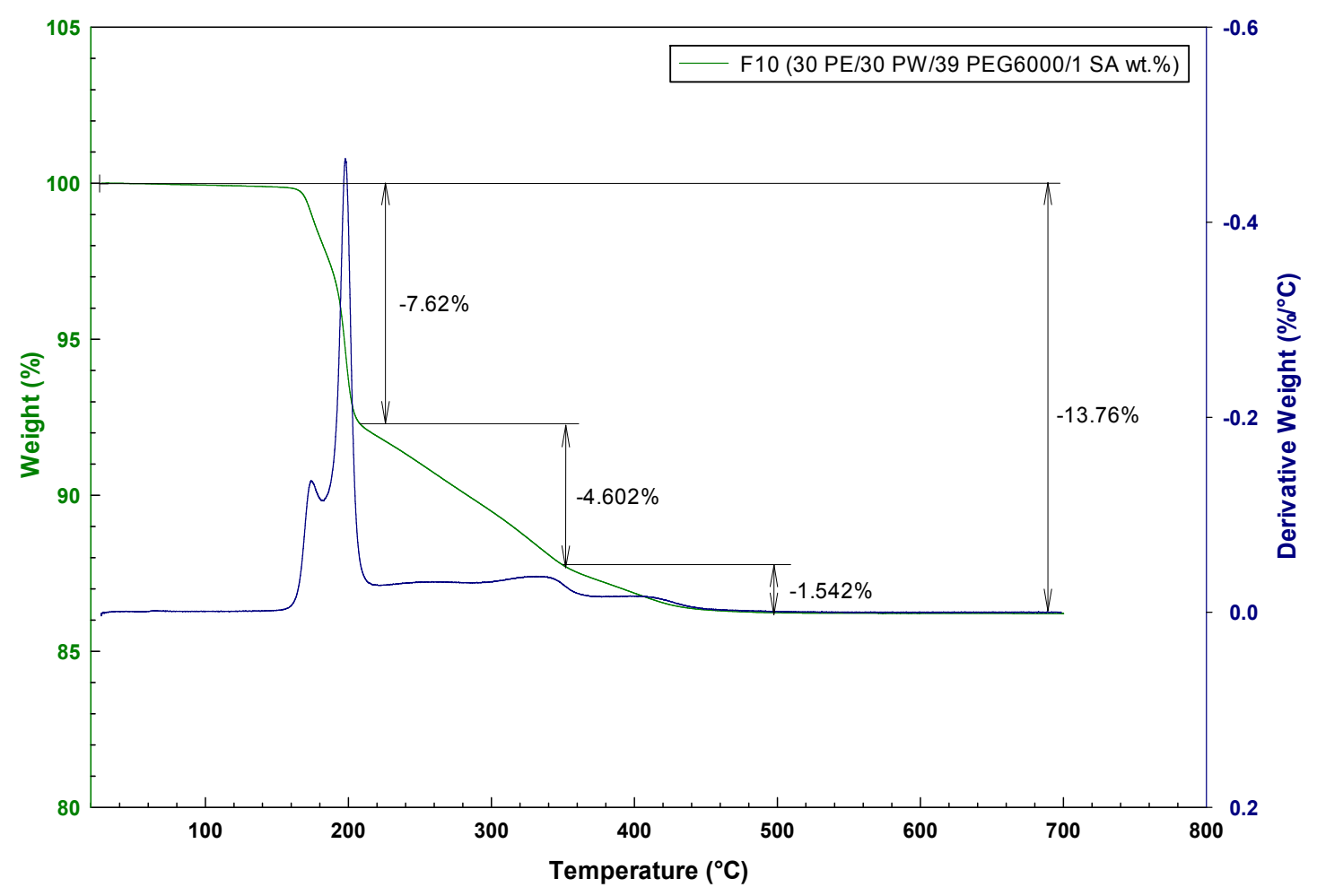

Typical feedstocks developed by using binder systems with $\mathrm{PW}$ and $\mathrm{CW}$ as a backbone binders are F17 (45 PW/50 PEG6000/5 SA wt.\%) and F22 (10 PW/40 CW/10 PEG1000/14 PEG2000/25 PEG6000/1 SA wt.\%), respectively. The feedstock F17 with higher amount of PW and high molecular PEG6000 shows a sharp significant drop of $10.21 \%$ at $174{ }^{\circ} \mathrm{C}$. This tendency may lead to cracks and 
distortions in the sample, and thus must be avoided in further development of binder compositions for the application. The combination of different molecular weight PEG in feedstock F22 developed a slight decrease before the first degradation stage. The first reasonable weight drop starts at $195{ }^{\circ} \mathrm{C}$ corresponding to the degradation of PEG blend and passes to a gradual decrease as of the second stage.

Figure 2. TGA weight loss and corresponding derivative curve for F14 (20 PE/30 PW/10 PEG1000/15 PEG4000/22 PEG6000/3 SA wt.\%).

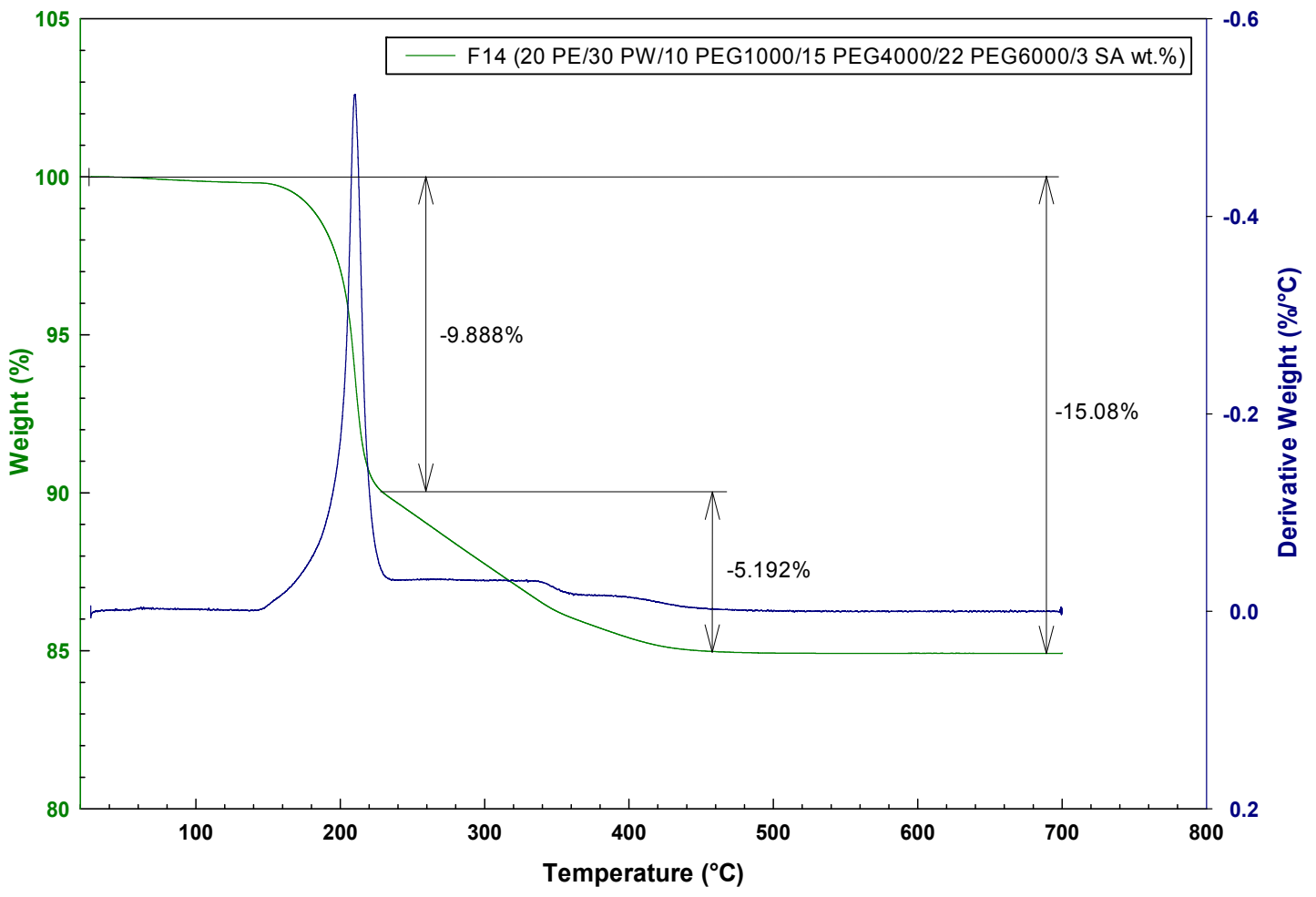

In this respect, the second stage represents the extraction of $\mathrm{CW}$, where the exhibited moderate decline is connected with narrow setting range of $\mathrm{CW}$. It shows that the noticeable unwanted rapid drop at the first stage for feedstock F17 can be superceded by proper choice of component's mass distribution.

The presence of the third peak in -dTGA curves situated in the temperature range $330-360{ }^{\circ} \mathrm{C}$ clearly correlates with the presence of reasonable amounts of the high molar mass polymer component in the binder. No peak was observed for compositions having less than $25 \mathrm{wt} . \%$ of PE and less than $30 \mathrm{wt} . \%$ of $\mathrm{CW}$ in the binder. The first step of the thermal decomposition of the binder's polymer component is manifested in this narrow temperature region regardless of the chemical nature of the polymer used which testifies to the importance of the transport phenomena in the fired body.

The highest activation energy is needed for decomposition and volatilisation of residual binder mass inside the fired body at the end of the thermal debinding process which is manifested by a decomposition step above $400{ }^{\circ} \mathrm{C}$ corresponding to the second decomposition step known for PE and $\mathrm{CW}$. The scatter range of the peak maxima from $440-475{ }^{\circ} \mathrm{C}$ is narrow and most likely not influenced by the aluminium oxide filler level regardless of the use of PE or CW, like in the previous step. According to the total mass loss, full binder extraction was achieved for all examined materials. 


\subsection{Thermal Analysis of Water Debinded Feedstocks}

The study of TGA results for previously water debinded feedstocks is summarized in Table 4.

Table 4. Water debinded feedstock thermal degradation peaks in percentage of weight loss.

\begin{tabular}{ccccccc}
\hline \multirow{2}{*}{ Feedstock } & \multicolumn{2}{c}{ Peak 1 } & \multicolumn{2}{c}{ Peak 2 } & \multicolumn{2}{c}{ Peak 3 } \\
\cline { 2 - 7 } & {$\left[{ }^{\circ} \mathbf{C}\right]$} & {$[\mathbf{w t . \%}]$} & {$\left[{ }^{\circ} \mathbf{C}\right]$} & {$[w t . \%]$} & {$\left[{ }^{\circ} \mathbf{C}\right]$} & {$[$ wt.\%] } \\
\hline F2 & 210 & 0.93 & 225 & 5.75 & 487 & 4.86 \\
F6a & 200 & 2.43 & 364 & 11.4 & 475 & 1.91 \\
F7a & 170 & 2.48 & - & - & 477 & 13.52 \\
F9 & 170 & 1.33 & 250 & 6.1 & 480 & 3.56 \\
F10 & 220 & 0.16 & 229 & 5.77 & 490 & 4.44 \\
F14 & 199 & 0.89 & 220 & 6.57 & 494 & 4.64 \\
F16 & 175 & 1.17 & 252 & 10.1 & 449 & 4.19 \\
F22 & 208 & 1.8 & 230 & 6.37 & 467 & 5.35 \\
\hline
\end{tabular}

The water debinding stage imparts the water-soluble binder components and can be used for two purposes, i.e., as the technological debinding step opening pores serving as channels for volatiles generated during firing. and as the analytical tool for clarification of the role of the aforesaid extractables in the feedstock. A remarkable weight drop was obviously observed for the samples with high vol.\% of low molecular PEG binders. The samples with high content of PEG and low content of PW showed the highest water debinding results, and vice versa for the samples with high vol.\% of PW. PW and PE have the same hydrophobic behaviour but the correlation of debinding efficiency with PW rather than with $\mathrm{PE}$ points towards the role of $\mathrm{PW}$ as the key blocking agent in the investigated composition framework which may be due a better miscibility of the low molecular compounds with other component of the material system. The same tendency was observed for binders containing the $\mathrm{CW}$ although the CW can be considered as less hydrophobic than PE.

At first sight, the thermal decomposition of the feedstocks was influenced by the water debinding simply by removal of the low molecular PEG component and only three decomposition steps are manifested in the TGA curves. Indeed, the diminishing or disappearance of the low temperature peaks from -dTGA curves as well as depreciation of the observed mass loss steps correlates with the efficiency of the water debinding procedure discussed in the above paragraph. The changes in the mass loss proportions can be explained by the selectivity of the water debinding which removes watersoluble components. Moreover, the peaks seem to be slightly shifted towards lower temperatures indicating thus easier mass removal from the fired body in this temperature region. It can be assumed that the water debinding opened pores into the specimen body by removal of the extractable part of the binder [22].

Thorough analysis of the data in Table 4 in comparison with Table 3 showed that the thermal degradation process appearing in the range between 300 and $400{ }^{\circ} \mathrm{C}$ virtually vanishes. As shown in the section above, this decomposition step may be ascribed to the insoluble polymer component of the binder, hence it was not expected that it can be affected by water debinding. One of the effects of the water bath treatment can be not only easier removal of low molecular fractions, but also a faster and 
better densification of the fired body which can increase the barrier against high molecular binder components decomposition and shift the respective mass loss step to higher temperature.

The high temperature decomposition step between 400 and $500{ }^{\circ} \mathrm{C}$ was shifted slightly to higher temperatures $\left(467-485{ }^{\circ} \mathrm{C}\right)$. Such a shift corresponds to an increase of activation energy of the respective process which supports the explanation given in the previous paragraph. The high temperature final step corresponds to the decomposition of residuals entrapped strongly inside the fired body thus requiring a higher activation energy to be removed from the specimen. The mass loss connected with this decomposition step remained unchanged in samples which contained higher amounts of low or moderate molar mass PEG and lower amount of high molecular PEG. The proportion between PE and PW plays important role too. Water debinded specimen F7a which has the highest content of high molecular weight components, i.e., both PE and PEG, showed an enormous increase of mass degraded in this step. A similar correlation was found for the proportion of $\mathrm{CW}$ and high molecular PEG. It can be summarized that a balanced proportion of PEG components results into the low high temperature mass loss. According to that the use of PEG with broad molecular mass distribution can be suggested for future experiments. However, it must be pointed out that the aforesaid rule of thumb only works for compounds with balanced proportions between PE and PW or compositions with higher amounts of $\mathrm{CW}$ and small additions of PW. The latter conclusion supports the effort to replace synthetic materials by renewable natural stocks. As in the simple thermal debinding, full binder extraction was achieved for all examined water debinded materials.

\section{Experimental}

\subsection{Materials}

High compressible superground aluminum oxide powder (MARTOXID MR70, Albemarle Corp, Barton Rouge, LA, USA) with tap density $2.2-2.4 \mathrm{~g} / \mathrm{cm}^{3}$, sintered density $3.74-3.95 \mathrm{~g} / \mathrm{cm}^{3}$ and specific surface $6-10 \mathrm{~m}^{2} / \mathrm{g}$ was used. The the particle size distribution (Figure 3) was measured on a Laser Diffraction Particle Sizing Instrument (Mastersizer 3000, Malvern Instruments Ltd, Malvern, UK).

Figure 3. $\mathrm{Al}_{2} \mathrm{O}_{3}$ powder particle size distribution curve (Mastersizer 3000).

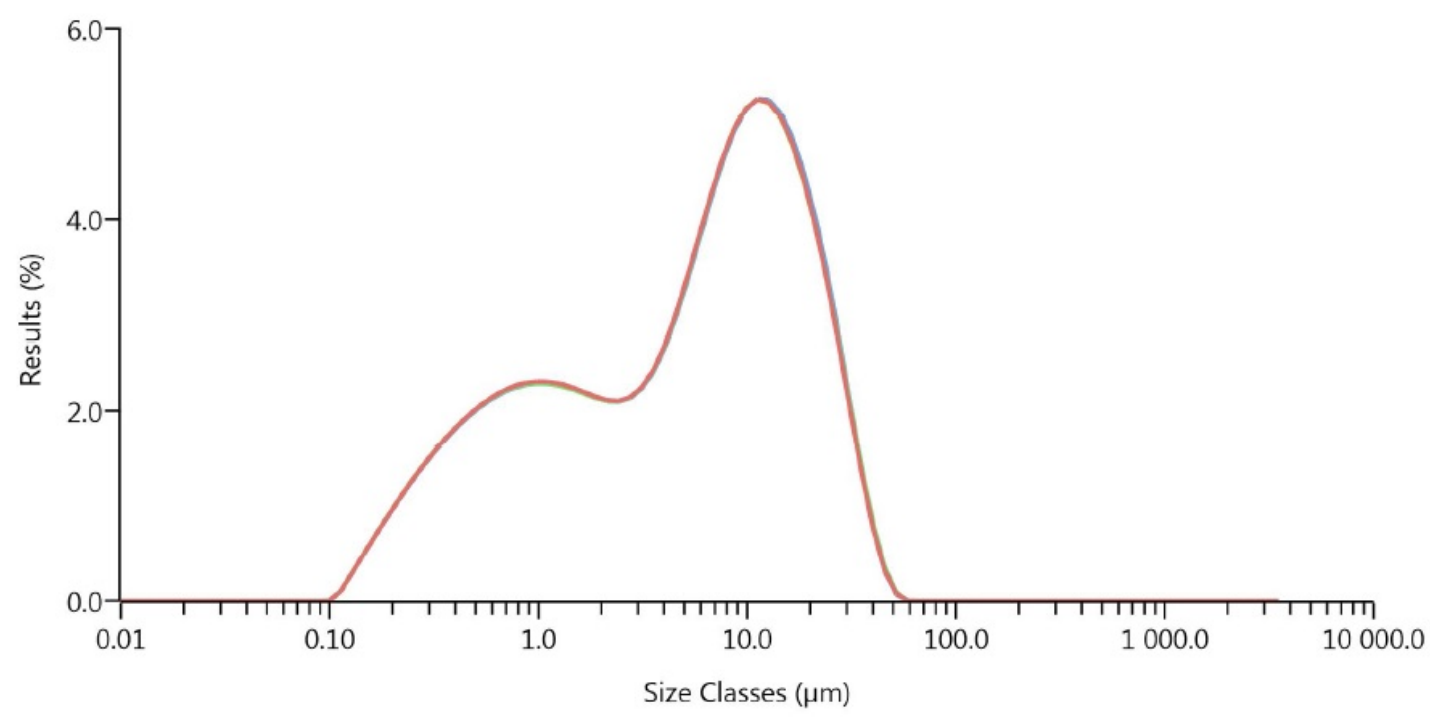


The properties of polymers serving as a binder components - low density polyethylene (PE), paraffin wax (PW), carnauba wax $2442(\mathrm{CW})$, polyethylene glycols differing in their molecular weights (PEG1000, PEG4000, PEG6000) and stearic acid (SA) - are summarized in Table 5. Peak melting temperature was obtained from differential scanning calorimetry (Mettler Toledo DSC1, Greifensee, Switzerland) with heating-cooling rate of $10{ }^{\circ} \mathrm{C} / \mathrm{min}$ on aluminium pan in nitrogen atmosphere with $(60 \mathrm{~mL} / \mathrm{min})$ flow. Apparent shear viscosity was determinated with a rotational rheometer Bohlin Gemini CVOR $150 \mathrm{CE} / \mathrm{WIN}$ (Malvern Instruments) using a cone-plate geometry (cone angle $2.5^{\circ}$, plate diameter $40 \mathrm{~mm}$ ) in an air atmosphere. Measurements were carried out at $140{ }^{\circ} \mathrm{C}$ and shear rate of $80 \mathrm{rad} / \mathrm{s}$. Other properties were taken from the material data sheets provided by suppliers.

Table 5. Characteristic properties of the binder components.

\begin{tabular}{cccccccc}
\hline Name & PE & PW & CW & PEG1000 & PEG4000 & PEG6000 & SA \\
\hline $\begin{array}{c}\text { Density }\left[\mathrm{g} / \mathrm{cm}^{3}\right] \\
\text { ISO 1133 }\end{array}$ & 0.918 & 0.9 & 0.97 & 1.09 & 1.41 & 1.21 & 0.85 \\
$\begin{array}{c}\text { Melting Temperature } \\
\quad\left[{ }^{\circ} \mathrm{C}\right]\end{array}$ & 108 & 58 & 84 & 32 & 62 & 62 & 70 \\
$\begin{array}{c}\text { Molecular Weight } \\
\quad[\mathrm{g} / \mathrm{mol}]\end{array}$ & 250,000 & 400 & 1000 & 1000 & 4000 & 6000 & 284 \\
\begin{tabular}{l} 
Viscosity $[\mathrm{kPa} . \mathrm{s}]$ \\
\hline
\end{tabular} & 20 & 2 & 12 & 10 & 72 & 147 & 3 \\
\hline
\end{tabular}

\subsection{Preparation of Feedstocks}

A Brabender plasticorder with a mixing chamber of $50 \mathrm{~cm}^{3}$ volume was used for mixing the components. Mixing temperature varied between 100 and $160{ }^{\circ} \mathrm{C}$ depending on the composition of mixed feedstock, with the mixing time of $30 \mathrm{~min}$ at a speed $20 \mathrm{rpm}$. In sum 29 feedstock compositions were prepared, with powder loadings $\left(\phi_{\mathrm{m}}\right)$ varying between 84.2 and 86.5 wt.\%.

\subsection{Methods}

The thermal degradation properties were studied using a thermogravimetric analyzer TA TGA Q500 (TA Instruments, New Castle, DE, USA) with a platinum pan in an air atmosphere with a constant heating rate of $10^{\circ} \mathrm{C} / \mathrm{min}$ in temperature range between 30 and $700{ }^{\circ} \mathrm{C}$. Purge gas flow on the balance and sample were $40 \mathrm{~mL} / \mathrm{min}$ and $60 \mathrm{~mL} / \mathrm{min}$, respectively. Feedstock specimens of irregular form were tested. The mass varied between 45 to $58 \mathrm{mg}$ which assured minimization of the specimen weight on the thermogravimetric analysis. In the case of the combined debinding route testing the debinding of water soluble components of binder system components was performed at $60{ }^{\circ} \mathrm{C}$ for one hour prior to the thermal debinding.

\section{Conclusions}

From the results it may be concluded that low molecular PEG enhances the early thermal degradation and opens a network of pores in the sample which allows defect free debinding of residual backbone binder. A well balanced ratio between different PEG fractions is required for best 
performance of the debinding procedure, both for single thermal or two step debinding involving a water bath prior the thermal step. It suggests future use of polydispersive PEG.

The $\mathrm{CW}$ as a backbone ensures gradual and stage followed debinding process, while retaining the shape of the component up to late debinding - early sintering stage due to its very narrow setting range. In next, the application of $\mathrm{CW}$ allows one to decrease the amount of $\mathrm{PW}$ in the composition.

The thermal debinding process at temperatures above $300{ }^{\circ} \mathrm{C}$ is not influenced by the choice of PE or CW but depends exclusively on transport phenomena in the highly filled system. It can be advantageously influenced by the water debinding step application. Besides it may successfully replace the polyethylene as a backbone binder and lower the consumption of PW, so carnauba wax would be the most appropriate choice since it serves as a renewable natural resource which is an outstanding property from an environmental perspective.

\section{Acknowledgments}

This article was written with the support of Operational Program Research and Development for Innovations co-funded by the ERDF and national budget of Czech Republic, within the framework of project Centre of Polymer Systems (reg. number: CZ.1.05/2.1.00/03.0111) and of Operational Program Education for Competitiveness co-funded by the European Social Fund (ESF) and national budget of Czech Republic, within the framework of project Advanced Theoretical and Experimental Studies of Polymer Systems (reg. number: CZ.1.07/2.3.00/20.0104). The author D.B. would like to acknowledge the support of the internal grant of Tomas Bata University in Zlin No. IGA/FT/2014/ and support of Visegrad Fund.

\section{Author Contributions}

Berenika Hausnerova - state of art, idea and concept of the paper, compositions of feedstocks; Ivo Kuritka - discussion of the TGA results and conclusions; Davit Bleyan - experimental.

\section{Conflicts of Interest}

The authors declare no conflict of interest.

\section{References}

1. Onbattuvelli, V.P.; Vallury, S.; McCabe, T.; Park, S.J.; Atre, S.V. Properties of SiC and AlN feedstocks for the powder injection moulding of thermal management devices. PIM Int. 2010, 4, 64-70.

2. Chung, C.; Rhee, B.; Cao, M.; Liu, C. Requirements of binder for powder injection molding. In Advances in Powder Metallurgy; In Proceedings of Powder Metallurgy Conference and Exhibition, San Diego, USA, 11-14 June 1989; Gasbarre, T.G., Jandesca, W.F., Eds.; Metal Powder Industries Federation: Princeton, NJ, USA, 1989; pp. 67-78.

3. Tseng, W.J.; Hsu, C.K. Cracking defect and porosity evolution during thermal debinding in ceramic injection moldings. Ceram. Int. 1999, 25, 461-466. 
4. Zhang, J.; Edirisinghe, M.; Evans, J. A catalogue of ceramic injection moulding defects and their causes. Ind. Ceram. 1989, 9, 72-82.

5. Hausnerova, B.; Vltavska, P.; Sedlacek, T. Pressure-Affected Flow Properties of Powder Injection Moulding Compounds. Powder Technol. 2009, 194, 192-196.

6. Onbattuvelli, V.P.; Enneti, R.K.; Park, S.; Atre, S.V. The effects of nanoparticle addition on binder removal from injection molded aluminum nitride. Int. J. Refract. Metals Hard Mater. 2013, 36, 77-84.

7. Hausnerova, B.; Marcanikova, L.; Filip, P.; Saha, P. Optimization of powder injection molding of feedstock based on aluminum oxide and multicomponent water-soluble polymer binder. Polym. Eng. Sci. 2011, 51, 1376-1382.

8. Trunec, M.; Cihlar, J. Thermal removal of multicomponent binder from ceramic injection mouldings. J. Eur. Ceram. Soc. 2002, 22, 2231-2241.

9. Krauss, V.A.; Oliveira, A.A.M.; Klein, A.N.; Al-Qureshi, H.A.; Fredel, M.C. A model for PEG removal from alumina injection moulded parts by solvent debinding. J. Mater. Process. Technol. 2007, 182, 268-273.

10. Voorhees, K.J.; Baugh, S.F.; Stevenson, D.N. The thermal degradation of poly(ethylene glycol)/poly(vinyl alcohol) binder in alumina ceramics. Thermochim. Acta 1996, 274, 187-207.

11. Huang, M.S.; Hsu, H.C. Effect of backbone polymer on properties of 316L stainless steel MIM compact. J. Mater. Process. Technol. 2009, 209, 5527-5535.

12. Hsu, K.C.; Lin, C.C.; Lo, G.M. Effect of wax composition on injection moulding of 304L stainless steel powder. Powder Metall.1994, 37, 272-276.

13. Yang, W.W.; Hon, M.H. In situ evaluation of dimensional variations during water extraction from alumina injection-moulded parts. J. Eur. Ceram. Soc. 2000, 20, 851-858.

14. Yang, W.W.; Yang, K.Y.; Hon, M.H. Effects of PEG molecular weights on rheological behavior of alumina injection molding feedstocks. Mater. Chem. Phys. 2003, 78, 416-424.

15. Ren, S.B.; He, X.B.; Qu, X.H.; Humail, I.S.; Li, Y. Effects of binder compositions on characteristics of feedstocks of microsizedSiC ceramic injection moulding. Powder Metall. 2007, 50, 255-259.

16. Persson, H.; Hausnerova, B.; Nyborg, L.; Rigdahl, M. Rheological and thermal properties of a model system for PIM. Int. Polym. Proc. 2009, 24, 206-212.

17. Knapp, A.M.; Halloran, J.W. Binder removal from ceramic-filled thermoplastic blends. J. Am. Ceram. Soc. 2006, 89, 2776-2781.

18. Chartier, T.; Delhomme, E.; Baumard, J.F. Mechanisms of binder removal involved in supercritical debinding of injection moulded ceramics. J. Phys. III 1997, 7, 291-302.

19. Maximenko, A.; Biest, O. Finite element modelling of binder removal from ceramic mouldings. J. Eur. Ceram. Soc. 1998, 18, 1001-1009.

20. Seeger, M.; Gritter, R.J. Thermal decomposition and volatilization of poly( $\alpha$-olefins). J. Polym. Sci.: Polym. Chem. 1977, 15, 1393-1402.

21. Wright, J.K.; Evans, J.R.G. Kinetics of the oxidative degradation of ceramic injection-moulding vehicle. J. Mater. Sci. 1991, 26, 4897-4904.

22. Craig, R.G.; Eick, J.D.; Peyton, F.A. Properties of natural waxes used in dentistry. J. Dent. Res. 1965, 44, 1308-1316. 
23. Han, S.; Kim, C.; Kwon, D. Thermal/oxidative degradation and stabilization of polyethylene glycol. Polymer 1997, 38, 317-323.

\section{Appendix}

Figure A1. TGA weight loss curves for binders used.

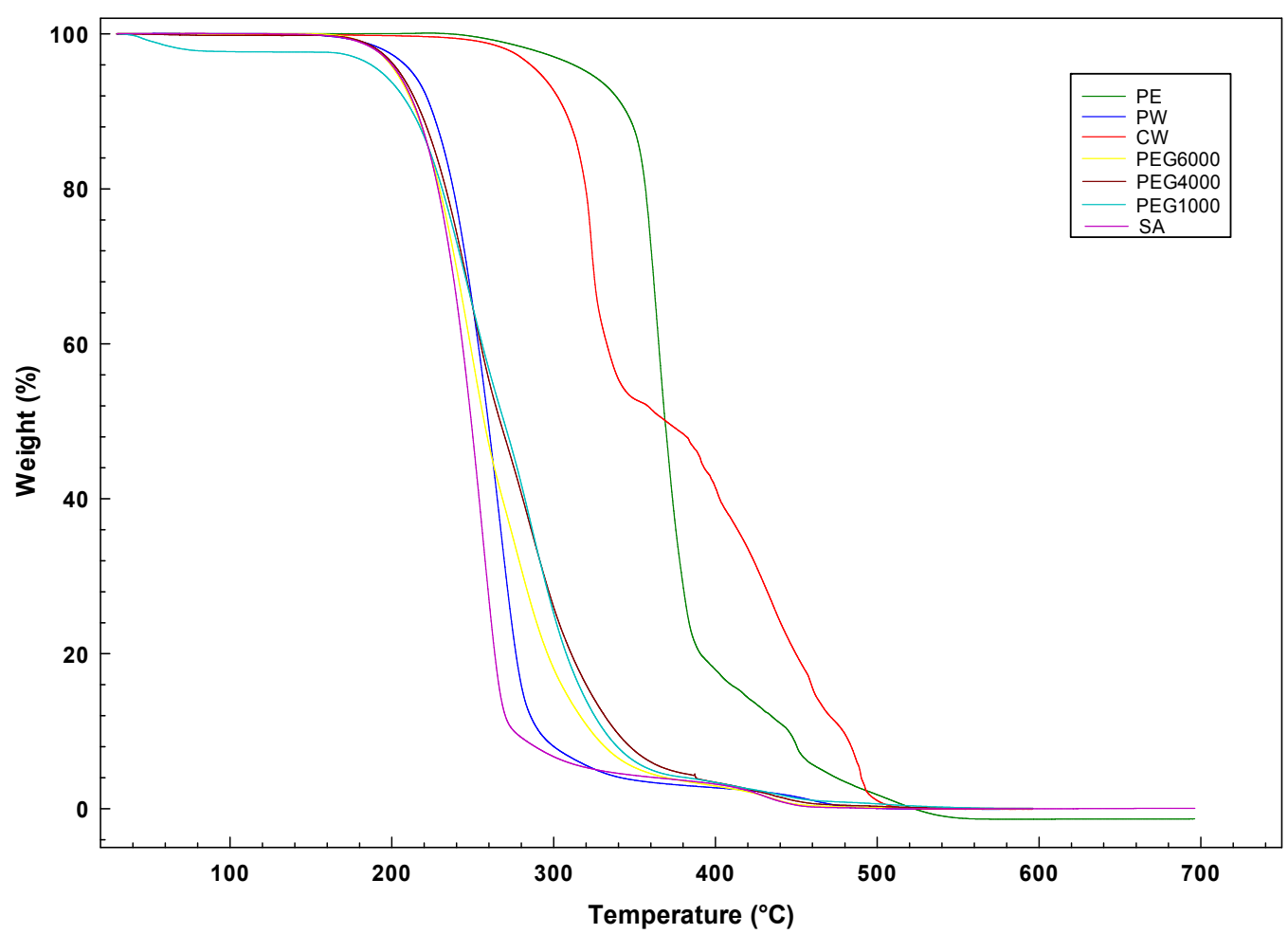

Sample Availability: Samples of all compounds F1-F22 are available from the authors.

(C) 2014 by the authors; licensee MDPI, Basel, Switzerland. This article is an open access article distributed under the terms and conditions of the Creative Commons Attribution license (http://creativecommons.org/licenses/by/3.0/). 